\title{
Project and Change Management Success Factors from Malaysian Government Departments and Agencies Perspective
}

\author{
Alyaa Ghanim ${ }^{1}$, Fatima Munassar ${ }^{2}$, Abdul Rahman Ahmad Dahlan ${ }^{3}$ \\ ${ }^{I}$ (IS department, International Islamic University Malaysia, Malaysia) \\ 2 (IS department, International Islamic University Malaysia, Malaysia) \\ ${ }_{3}^{3}$ (Senior Academic Fellow, International Islamic University Malaysia, Malaysia)
}

\begin{abstract}
Project is considered as a core element in any organization and its continuity can be guaranteed through a successful change management. Confronting merciless challenges at the current time particularly at the market field, the emergency need has been raised to overcome those obstacles and step ahead on rivals. One way that most organizations have moved towards its capabilities and put the pressure on it to produce quality and optimal outcomes is ICT. Thus, various types of IT projects with variant intended objectives have been conducted. As being witnessed recently and noticed previously, that a lot of IT projects turned to fail due to several reasons. Additionally, way of life changes from time to time and people requirements have changed and become so complicated recently with the exposure to advanced technology that has been attached with our daily life activities. A survey has been conducted among some Malaysian Government departments and agencies to elicit the main factors which participate in the success of projects and what the importance level of implementing an effective change management over projects that lead to sustainability and productivity of the organizations. This survey results have been received as a quantitative feedback that makes it clear to make a conclusion.
\end{abstract}

Keywords - Project, Project Management, Project success, Change Management,

\section{INTRODUCTION}

Government sectors are the most potential bodies in the society due to their duties towards their people. Organizations are continuing to grow specially government bodies where the numbers of citizen keep growing. As being a government organization, it becomes so critical in providing optimal services and products that serve people needs. Reasoning that people of the society are among the stakeholders that share the resources with the government, therefore establishing any new services will consume people's money and resources.

Observing how the power of technology could change traditional way of doing things and facilitate tremendous activities to obtain intended requirements, organizations moved to embed these technologies in their cultural and consider them as one of the organizational strategic plan.

Numbers of IT project have been established to produce efficient deliverables with limited resources and within specified period of time. However, it has been witnessed that projects failure rate has increased recently which makes it very disappointing matter. Researchers are trying to figure out the most common reasons of project failure by analyzing the market trends and factors that may contribute.

\section{Project Vs. Project Management}

People misconceive in differentiating between project and project management. Project is built to achieve several objectives that can be established through series of unique, complex and interrelated processes that consume resources. Project needs to be completed within specific time and allocated budget. In contrast, project management is responsible to ensure the smoothness of the implementation of the project by having an effective monitoring and contorting techniques over the project implementation stages. Project management seeks to produce an efficient project that satisfies and meets its desired objectives by defining the requirements, allocating required resources, planning the work structures, measuring the progress, having continuous monitoring process over the project [1][13].

In few words, projects are task oriented that aim to add value to the organizations and contribute to the sustainability of the organizations which tend to be long-term nature. This value can be seen as financial, marketing or technical benefits that can last longer over several years depending on the project itself. While project management is planning and controlling orientation that concern with on-time delivery bound to determined required completion time and allocated budget needed plus meeting the satisfaction level of the customers. Thus, project management is seen as short-term process where its duty will be ceased once the desired deliverables are achieved [1][13]. 
Since the project is long-term nature and project management is short-term nature, the importance of change management has been highlighted. From this point we can understand that project is monitored by these two potential managements that struggle ensure the effectiveness and efficiency of the project.

\section{Change Management}

Encountering the globalization, pressure of advanced technology, harsh competition besides the rapid changing occurring over various aspects of life, all these issues have raised the emergent call for strategic level of transformation need. Transformation process can happen over existent technology, culture, processes and organizational resources aiming to achieve optimal objectives resulting in the sustainability and organizational survival [2].

Since project is long-term, the need for an effective change management has been highlighted. According to Moran and Brightman, they defined change management as "the process of continually renewing an organization's direction, structure, and capabilities to serve the ever-changing needs of external and internal customers" [2].

According to Burnes (2004) change is an ever-present feature of organizational life, both at an operational and strategic level [2].

Change becomes a normal phenomenon where organizations are facing it frequently; therefore, there is no escape from being changed to cope with the current time acceleration. The duty of assuring the proper utilization and implementation for the project and facilitating the projects benefits to be obtained as desired is on change management.

Although the need for change becomes essential to stay ahead on rivals and gain competitive advantage, yet numbers of effective organizational change remain very few [3].

There are several phases where change should go through to ensure the smoothness of change management implementation.

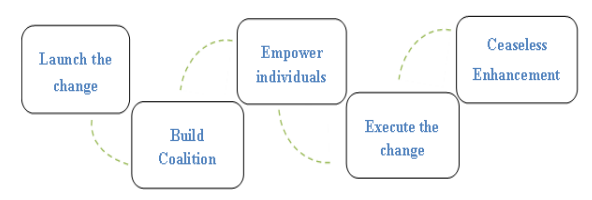

Fig (1): Change Management Framework

\section{Project Success}

Judging on a project to be either successful or failure is varied from one point of view to another. It has been known that as long as the project meets the iron triangle constraints which are time, budget and scope is considered a successful project [4].

After a while, the successful criteria of the project have been expanded to include other constraints such as quality, risk, resources and customer satisfaction besides the previous constraints [4].

Recently it has been discovered that there are lots of factors that contribute to the success of the project. For instance, having proper project management, conducting an effective communication, planning optimal risk management, implementing an effective change management have tremendous impact on the success of the project.

\section{RESEARCH DESIGN}

A research design encompasses the methodology and procedures employed to conduct scientific research (Wikipedia) [5].

There are several types of research design, thus we have chosen some of them and we went through it. First step was conducting a literature review to have a clear picture regarding project nature and what kind of factors may contribute to its success.

Second, we selected a case study to narrow down our target to examine our hypothesis from small rang then we may enlarge it to encompass wider rang. A case study helps us to get a proper insight of particular situation. Third, a survey has been designed and distributed among few numbers of Malaysian government departments and agencies for the purpose of collecting data. Questioner has been created to focus on gathering quantitative types of data that makes easy to write an accurate conclusion.

\section{SURVEY FindingS}

This survey questionnaire has focused on only government sectors. This survey has been conducted involving 15 government departments and agencies with 50 responses. Survey has been divided into two main sections, first section concerns about project success factors and the second one is about change management. 
Illustrated graphs are shown below associating with the received percentage for each question. Before moving to the graphs, there are few terms need to be clarified in definition in table (1). There are several types of project management methodologies, and here is the explanation for each of them.

\begin{tabular}{|c|c|}
\hline Term & Definition \\
\hline In house/custom Methodology & $\begin{array}{l}\text { This context means developers working in a company } \\
\text { department, where software is used only by that company. }\end{array}$ \\
\hline $\begin{array}{l}\text { Prince1/Prince2(an acronym for } \\
\text { projects in controlled } \\
\text { environments, version } 1 \& 2)\end{array}$ & $\begin{array}{l}\text { Is defined as a methodology used to refer to the training and } \\
\text { accreditation of authorized practitioners of the methodology } \\
\text { who must undertake accredited qualifications to obtain } \\
\text { certification }\end{array}$ \\
\hline $\begin{array}{l}\text { PMBOK(Project Management } \\
\text { body of knowledge) }\end{array}$ & $\begin{array}{l}\text { PMBOK is a set of standard terminology and guidelines for } \\
\text { project. }\end{array}$ \\
\hline $\begin{array}{l}\text { RAD(Rapid application } \\
\text { development) }\end{array}$ & $\begin{array}{l}\text { RAD is a software development methodology that uses } \\
\text { minimal planning in favor of rapid prototyping. }\end{array}$ \\
\hline Agile & $\begin{array}{l}\text { Is defined as a set of software development methods based } \\
\text { on iterative and incremental development.[10] }\end{array}$ \\
\hline Extreme & $\begin{array}{l}\text { Is defined as a software development methodology which is } \\
\text { intended to improve software quality and responsiveness to } \\
\text { changing customer requirements.[11] }\end{array}$ \\
\hline Spiral & $\begin{array}{l}\text { Is defined as a software development process, its work to } \\
\text { combine both design and prototype together } \\
\text { And it is focus on risk assessment through breaking project } \\
\text { into smaller segments and provides more ease of } \\
\text { change.[12] }\end{array}$ \\
\hline Waterfall & $\begin{array}{l}\text { Is defined as a sequential development approach because it } \\
\text { is seen as flowing steadily downwards (like a waterfall) } \\
\text { through the phases of requirements analysis, design, } \\
\text { implementation, testing (validation), integration, and } \\
\text { maintenance.[12] }\end{array}$ \\
\hline Incremental & $\begin{array}{l}\text { It is a combining linear and iterative systems development } \\
\text { methodology with primary objective for each one in order } \\
\text { to reduce risk by breaking project into small segments. } \\
{[12]}\end{array}$ \\
\hline $\begin{array}{l}\text { WBS (work breakdown } \\
\text { structure) }\end{array}$ & $\begin{array}{l}\text { WBS means decomposes project into chunks to easy to } \\
\text { control and easy to implement[8] }\end{array}$ \\
\hline $\mathrm{CM}$ (change management) & $\begin{array}{l}\text { Is a process, tool and technique manage people-side to } \\
\text { improve business outcome.[14] }\end{array}$ \\
\hline
\end{tabular}

Table (1): illustrates terms of project management.

In Figure (2) below, It has be noticed that the most popular methodology that organization uses is in house/custom methodology which is registered more than a halve of overall rate, while a combination methodologies got the second level with 18\%. Furthermore, the percentage of PMBOK and Prince1/Prince2 methodology ranges are much similar with $15 \%$. As a result from this statistic, the successful methodology that organization prefers is to employ in house/custom methodology.

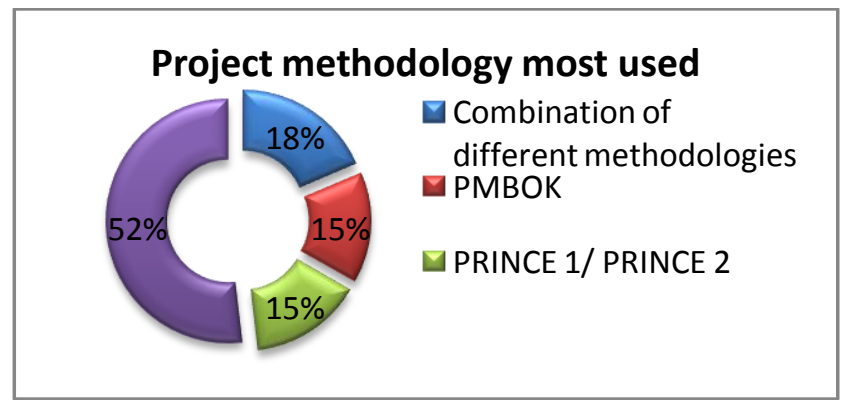

Figure (2): project methodology employment rate

Figure (3) below illustrates that which software methodology that organization frequently use. It is shown that prototyping occupied the highest rate which is 33\%, the second percentage belong to RAD methodology with $24 \%$. The third rate goes waterfall methodology with $17 \%$. Spiral software methodology acquires $14 \%$ from overall rate. Finally, merely number of responses mentioned that they use (incremental, extreme, agile) software methodology which is between $1 \%$ to $8 \%$ and none of the responses mention about other software. 


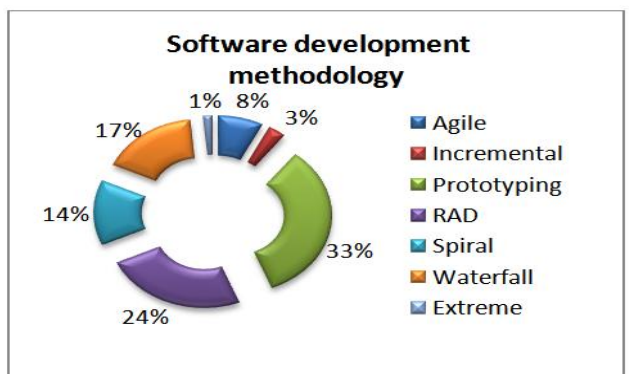

\section{Project Success}

Figure (3): Software development methodology conduct rate.

The Table (2) below explains that the potential criteria in project management by percentage and indicates which factor is highly important and which factor is less important during project implementation. It is ranged from 1 less important to 5 highly important.

\begin{tabular}{|l|l|l|l|l|l|}
\hline $\begin{array}{l}\text { How critical these factor } \\
\text { during the project } \\
\text { implementatipon process }\end{array}$ & $\mathbf{1}$ & $\mathbf{2}$ & $\mathbf{3}$ & $\mathbf{4}$ & $\mathbf{5}$ \\
\hline $\begin{array}{l}\text { Scope:is the expectation of } \\
\text { the cost, time, quality and } \\
\text { resources all of these } \\
\text { have been set and agreed.If } \\
\text { project change all these } \\
\text { excpectation change as } \\
\text { well. So the scope should } \\
\text { be defined accurately to } \\
\text { get right decision. }\end{array}$ & $0 \%$ & $2 \%$ & $62 \%$ & $36 \%$ \\
\hline $\begin{array}{l}\text { Cost:means the estimate } \\
\text { cost of the project, it } \\
\text { should be accurate as } \\
\text { possible. }\end{array}$ & $0 \%$ & $0 \%$ & $0 \%$ & $56 \%$ & $44 \%$ \\
\hline $\begin{array}{l}\text { Time:is the one of the } \\
\text { basic variable to project } \\
\text { delivery and is not fix } \\
\text { depend on the project if } \\
\text { the project change in this } \\
\text { case the time need to } \\
\text { extend. }\end{array}$ & $0 \%$ & $0 \%$ & $0 \%$ & $58 \%$ & $42 \%$ \\
\hline $\begin{array}{l}\text { Quality nis non negotiable } \\
\text { variable because if the } \\
\text { project needs high quality } \\
\text { the cost will be high while } \\
\text { if the quality is low then } \\
\text { the cost will be cheap. }\end{array}$ & $0 \%$ & $0 \%$ & $2 \%$ & $64 \%$ & $34 \%$ \\
\hline
\end{tabular}

Table (2): shows the potential criteria in project management.

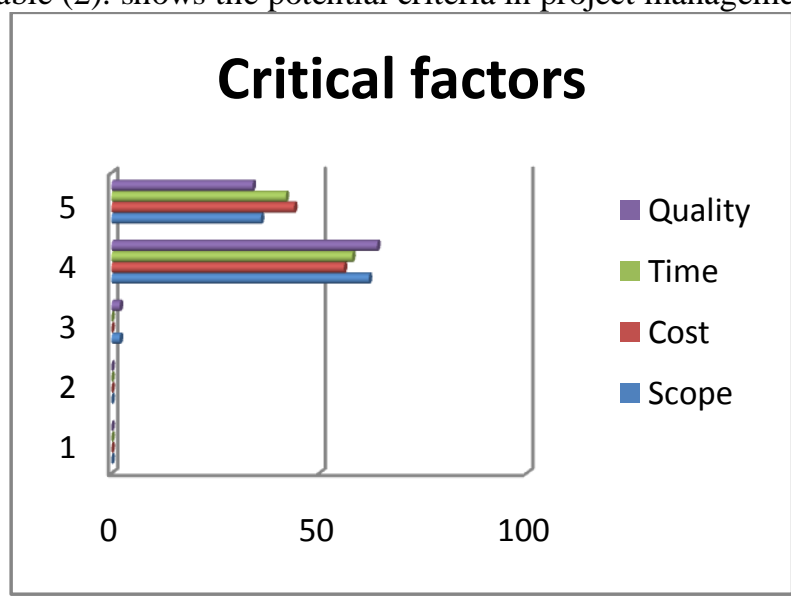

Figure (4): Critical factors during project implementation

From given information above, we can realize that those factors are highly important from their positive percentage rate and need a serious attention during the implementation of the project. 
Other factors also have been highlighted in the following table.

\begin{tabular}{|l|c|c|c|c|c|}
\hline $\begin{array}{l}\text { How critical these factor } \\
\text { during the project } \\
\text { implementatipon process }\end{array}$ & $\mathbf{1}$ & $\mathbf{2}$ & $\mathbf{3}$ & $\mathbf{4}$ & $\mathbf{5}$ \\
\hline Team Member & $0 \%$ & $0 \%$ & $6 \%$ & $76 \%$ & $18 \%$ \\
\hline Communication & $0 \%$ & $0 \%$ & $4 \%$ & $62 \%$ & $32 \%$ \\
\hline Risk blient Satisfaction & $0 \%$ & $0 \%$ & $6 \%$ & $72 \%$ & $22 \%$ \\
\hline Stakeholder Satisfaction & $0 \%$ & $0 \%$ & $2 \%$ & $62 \%$ & $36 \%$ \\
\hline $\begin{array}{l}\text { WBS(work breakdown } \\
\text { structure) }\end{array}$ & $0 \%$ & $0 \%$ & $4 \%$ & $74 \%$ & $22 \%$ \\
\hline $\begin{array}{l}\text { PMP(Project Management } \\
\text { Process) }\end{array}$ & $0 \%$ & $0 \%$ & $6 \%$ & $66 \%$ & $28 \%$ \\
\hline Organization Objectives & $0 \%$ & $0 \%$ & $2 \%$ & $72 \%$ & $26 \%$ \\
\hline
\end{tabular}

Table (3): illustrates the percentage of critical factors in project implementation.

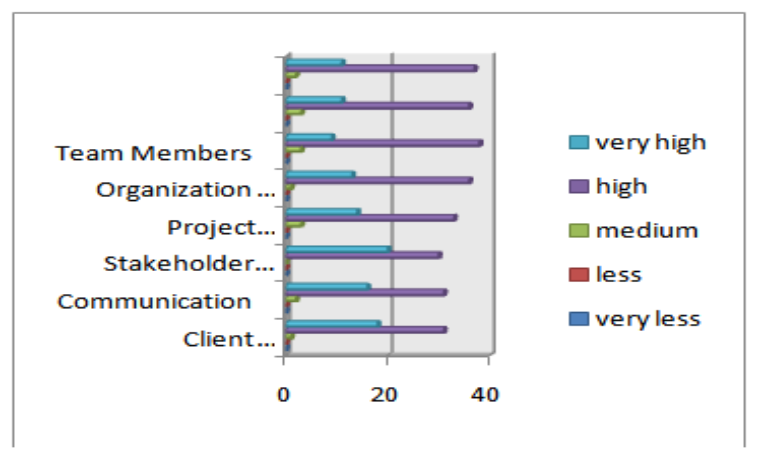

Figure (5): Other Critical factors during project implementation

As being realized from the above Figure (5) and percentages, these factors are potential during the implementation of the project where all of them got high positive rate.

\begin{tabular}{|l|c|c|c|c|c|}
\hline $\begin{array}{l}\text { How important are the } \\
\text { following criteria in } \\
\text { judging project success }\end{array}$ & $\mathbf{1}$ & $\mathbf{2}$ & $\mathbf{3}$ & $\mathbf{4}$ & $\mathbf{5}$ \\
\hline Completed on Time & $0 \%$ & $0 \%$ & $6 \%$ & $46 \%$ & $48 \%$ \\
\hline Completed on Budget & $0 \%$ & $0 \%$ & $6 \%$ & $54 \%$ & $40 \%$ \\
\hline Meeting the specification & $0 \%$ & $0 \%$ & $2 \%$ & $58 \%$ & $40 \%$ \\
\hline $\begin{array}{l}\text { Effective project } \\
\text { management process }\end{array}$ & $0 \%$ & $0 \%$ & $0 \%$ & $78 \%$ & $22 \%$ \\
\hline Proactive Team member & $0 \%$ & $0 \%$ & $2 \%$ & $78 \%$ & $20 \%$ \\
\hline Satisfy stakeholders needs & $0 \%$ & $0 \%$ & $4 \%$ & $56 \%$ & $40 \%$ \\
\hline Customer satisfaction & $0 \%$ & $0 \%$ & $6 \%$ & $40 \%$ & $54 \%$ \\
\hline $\begin{array}{l}\text { Third Parties affected by } \\
\text { project are satisfied }\end{array}$ & $0 \%$ & $0 \%$ & $10 \%$ & $66 \%$ & $24 \%$ \\
\hline
\end{tabular}

Table (4): critical criteria in judging project success

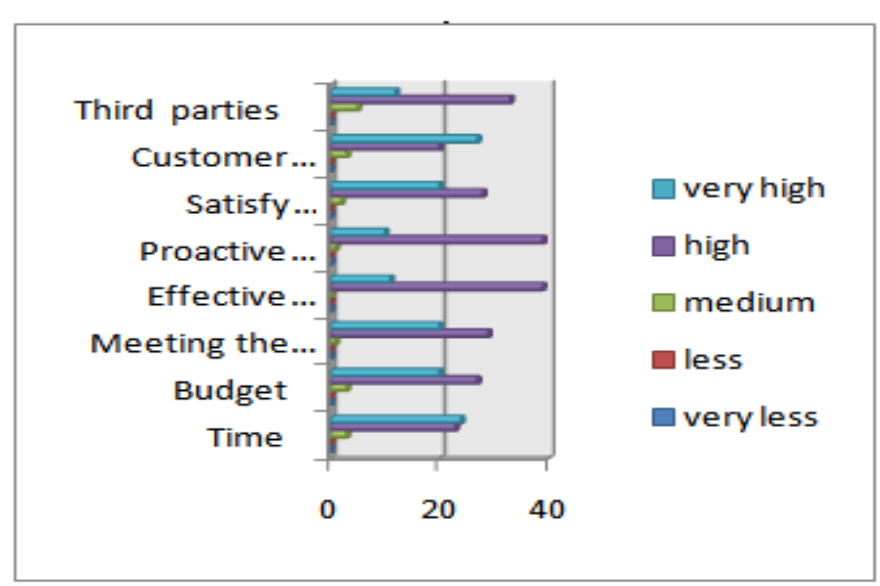

Figure (6): Other Critical criteria in judging project success 
Figure (6) shows three significant factors (time, budget and meeting the specification) that lead the project to be successful. Extracting from the table the percentages are very close half with $50 \%$ of participant said that the three factors are very important in successful project.

As shown in the Table (4) satisfying stakeholders, customer and third parties are essential during project implementation. The difference in percentage not huge among them, it is confirmed that these three issues are very important and none of people believe that they are less important. In addition, no one believes that EPMP (effective project management process) and PTM (proactive team member) are not significant in the project success. From statistics that conducted to prove this reality around $98 \%$ responses said that EPMP and PTM are very important success factor in project to be successful.

\section{Change management}

$>$ Please provide your opinion on the following statements:

Change is seen as: Opportunity/ Survival

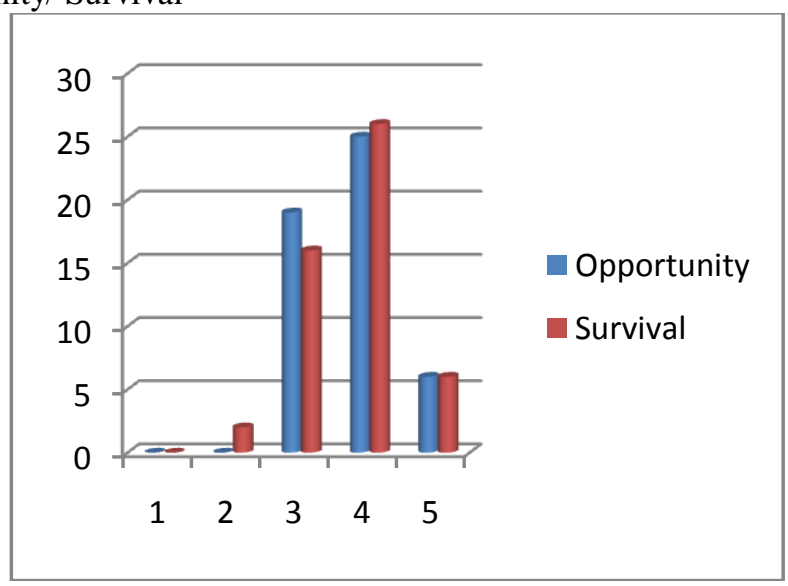

Figure (7): Change is seen either opportunity or Survival

As shown in the Figure (7) above, perceiving change as an opportunity or being a survival factor is slightly similar. According to the graph, it can be concluded that change does have an impact on the sustainability of the organization. Despite, few views have seen that change cannot be considered as one of the survival factors, the majority are more towards the change.

Change management is a vital component in your Organization of:

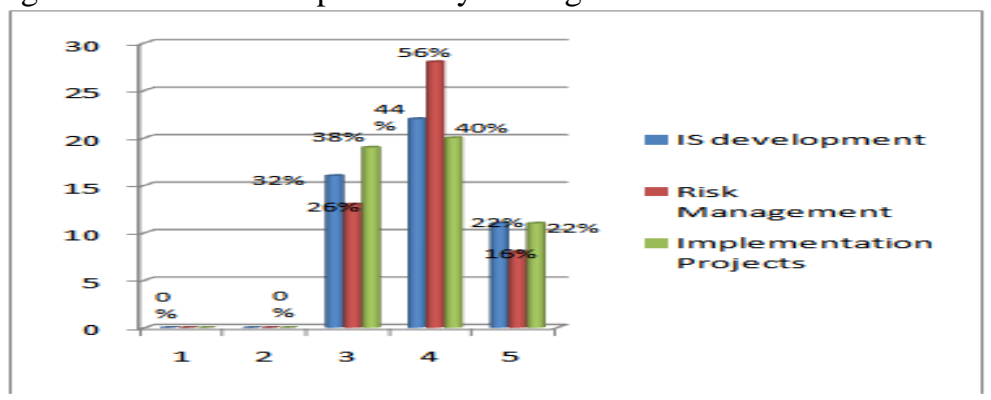

Figure (8): Change is vital component

As the majority, all agreed that CM is considered as a vital component that could have a potential impact on the success of the organization objectives. Eliciting from the graph, number of responses with low rate are very much close to zero.

Change management involves three elements:

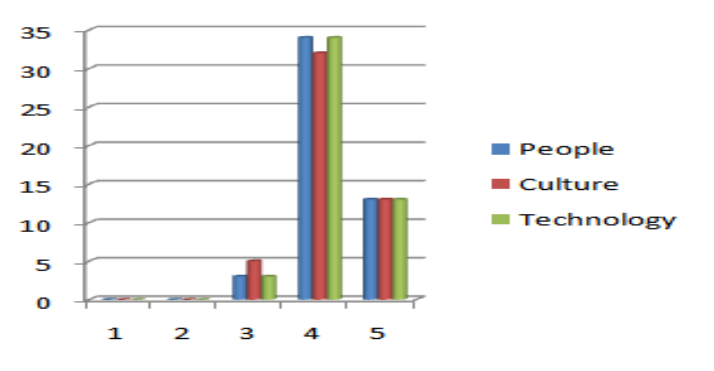

Figure (9): Change management involvement 
According to the Figure (9), it shows that the three elements are very much similar in terms of importance degree. People and technology elements got the higher results as potential elements in the Change management. Then the culture comes in the second level after people and technology. No one has given low rate that change management doesn't involve these three elements.

Change management should serve the need of:

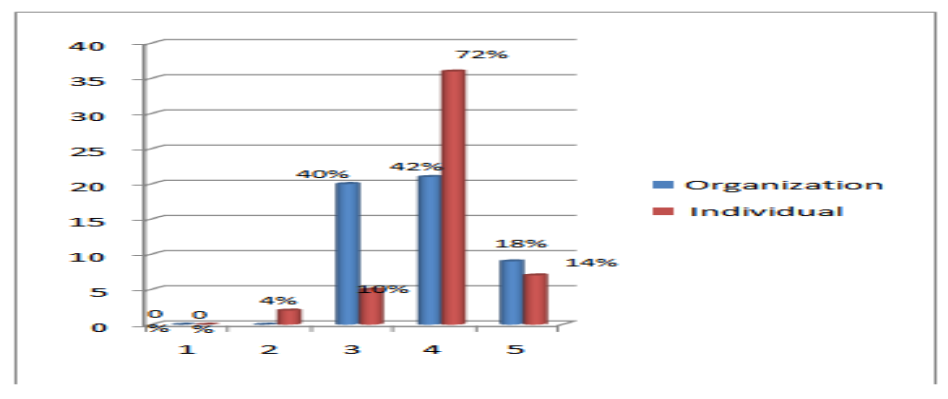

Figure (10): Change management serves both organization and individuals

Figure (10) shows that individual needs have got the higher level of importance in implementing the change compared to the organizational needs. It is shown that it is recommended that change should pay serious attention to individual interests mostly.

Change management evokes to improve from:

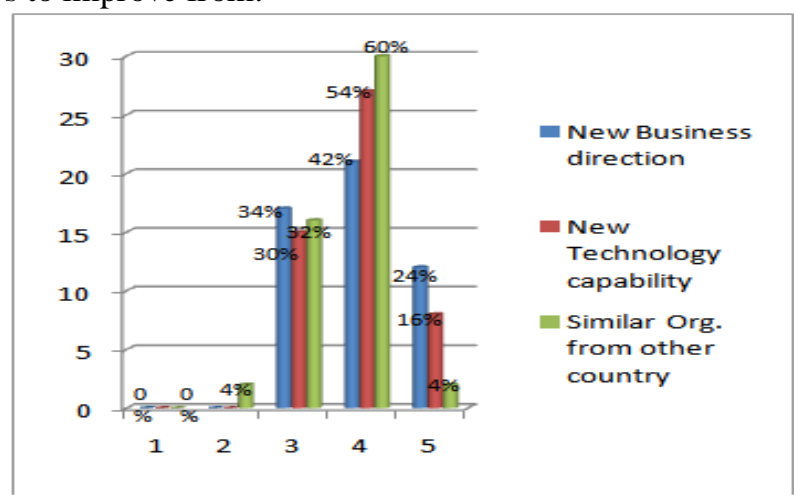

Figure (11): Change management benchmark.

From the Figure (11) above, it is shown that most organizations turn to improve by having others countries organizations as a benchmark. Then technology and new business direction come as second priority. Learning from others helps to obtain new ideas and overcome encountered problems and mistakes.

There are other elements should be taken care in the process of change management:

\begin{tabular}{|l|c|c|c|c|c|}
\hline $\begin{array}{l}\text { How important are the } \\
\text { following criteria in change } \\
\text { management process }\end{array}$ & $\mathbf{1}$ & $\mathbf{2}$ & $\mathbf{3}$ & $\mathbf{4}$ & $\mathbf{5}$ \\
\hline Must Understand & $0 \%$ & $0 \%$ & $46 \%$ & $38 \%$ & $16 \%$ \\
\hline A clear justification & $0 \%$ & $6 \%$ & $44 \%$ & $34 \%$ & $16 \%$ \\
\hline $\begin{array}{l}\text { Successful CM requires well } \\
\text { preparation for upcoming } \\
\text { challenges Organization }\end{array}$ & $0 \%$ & $4 \%$ & $42 \%$ & $34 \%$ & $20 \%$ \\
\hline $\begin{array}{l}\text { Teamwork and negative } \\
\text { leadership your }\end{array}$ & $0 \%$ & $2 \%$ & $44 \%$ & $38 \%$ & $16 \%$ \\
\hline $\begin{array}{l}\text { Stakeholders are change in yefore } \\
\text { towards the } \\
\text { organization }\end{array}$ & $0 \%$ & $0 \%$ & $28 \%$ & $54 \%$ & $18 \%$ \\
\hline $\begin{array}{l}\text { CM is required } \\
\text { implementing a IT project }\end{array}$ & $0 \%$ & $0 \%$ & $38 \%$ & $44 \%$ & $18 \%$ \\
\hline An effective Communication & $0 \%$ & $2 \%$ & $28 \%$ & $56 \%$ & $14 \%$ \\
\hline $\begin{array}{l}\text { Redeveloping existent and new } \\
\text { skills and attitude }\end{array}$ & $0 \%$ & $4 \%$ & $28 \%$ & $54 \%$ & $14 \%$ \\
\hline $\begin{array}{l}\text { CM must address organization } \\
\text { culture }\end{array}$ & $0 \%$ & $4 \%$ & $28 \%$ & $54 \%$ & $14 \%$ \\
\hline Quick-wins implication & $0 \%$ & $0 \%$ & $22 \%$ & $66 \%$ & $12 \%$ \\
\hline $\begin{array}{l}\text { CM requires an effective Risk } \\
\text { Management }\end{array}$ & $0 \%$ & $12 \%$ \\
\hline
\end{tabular}




\begin{tabular}{|l|l|l|l|l|l|}
\hline $\begin{array}{l}\text { Proper PM monitoring and } \\
\text { control required }\end{array}$ & $0 \%$ & $0 \%$ & $14 \%$ & $70 \%$ & $16 \%$ \\
\hline $\begin{array}{l}\text { New leaders and members } \\
\text { engagement }\end{array}$ & $0 \%$ & $2 \%$ & $48 \%$ & $30 \%$ & $20 \%$ \\
\hline Take an action & $0 \%$ & $0 \%$ & $32 \%$ & $52 \%$ & $16 \%$ \\
\hline $\begin{array}{l}\text { Commitment of competent of } \\
\text { staff and time constraint }\end{array}$ & $0 \%$ & $0 \%$ & $38 \%$ & $42 \%$ & $20 \%$ \\
\hline
\end{tabular}

Table (4): Rates of process change management.

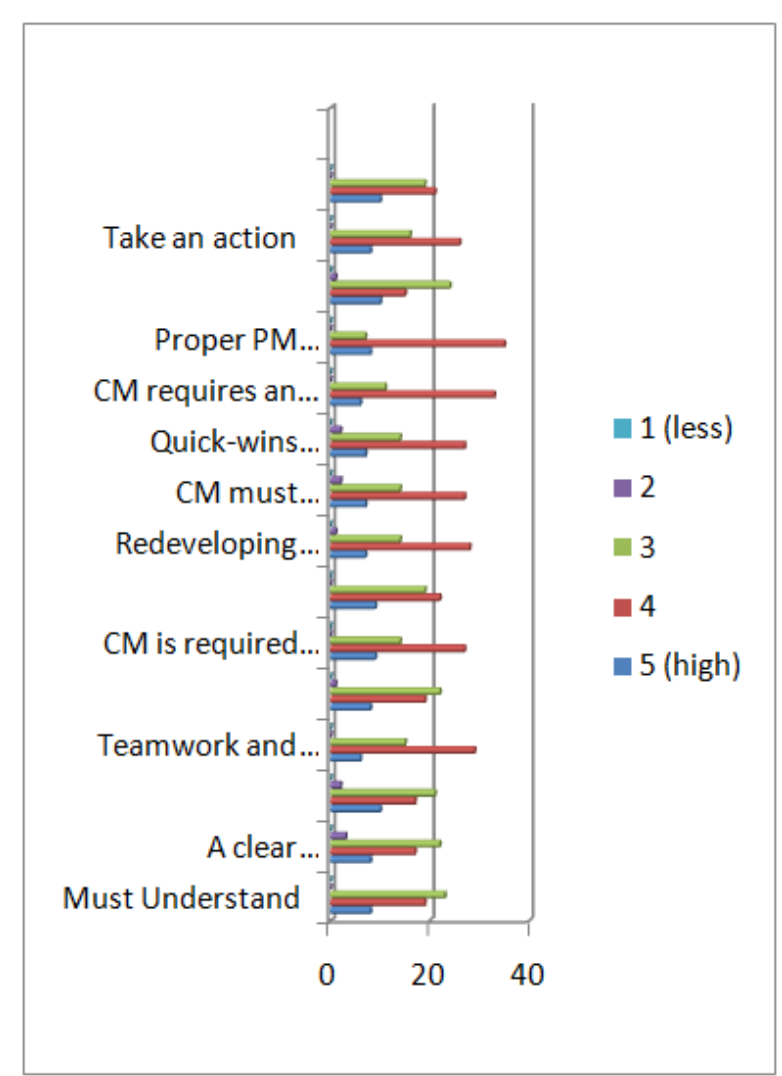

Figure (12): Other potential elements in change management process.

Providing a clear image of the importance of the change is the first step where its success will lead to the next potential steps. Based on the Figure (12), it shows that most of top management gets the responsibility to clarify the point of embracing the change. Furthermore, there are more positive responses which agreed that stakeholders must realize the importance and the necessity for conducting the change to cope with the current rapid advancement. For an effective change management planning, it should be able to address any upcoming challenges that may occur during the implementation of the change. This statement can be derived from the graph feedback where most positive responses support the process of well preparation CMP requirement.

Top management support and commitment beside the prop with talent skillful cooperative team members are very critical to any Change management implementation. It is explicit from the graph figures that the change requires teamwork and organization leadership.

Few responses disagreed by providing low rate response with the statement saying that stakeholders are negative towards the change. However, high positive responses did agree that generally stakeholders do not accept the change easily. Here the importance of effective communication is required to unveil the potential benefits that may gain from the implementation of the change.

Project change management should be prepared at the early stage for any project implementation seen from graph feedback. Therefore, CM requires an earlier attention that perceives how well the project will be implemented and its benefit are gained in the future.

High rate of positive responses have agreed that communication is very essential in conducting any project and change management. While very few keep being neutral, but no one has given low rate so far.

It is shown that the necessity for improving existent skills and developing and empowering team members with new skills and attitude are demanded. To overcome any new upcoming challenges at the current time, new technologies capability plus create skillful talent team members is very critical and required. 
Most have agreed that organization culture must be addressed when the change needs to be taken and implemented. For better Change implementation, change concept must be implicated and supported by the culture of the organization. Any adjustment and actions required should be done to produce optimal project that fulfilled its intended objectives

Eliciting from the graph, it is recommended to have quick-wins after successful completion for certain processes of the project to celebrate the joy of the victory and this surely will nurture them spiritually and push them to pay more effort effectively.

A high rate has been gone to the agreement that an effective risk management is very needed during the implementation of the change. Since the nature of conducting the change works with people and embracing new technology mostly, thus risks are more likely to occur such as people resistance, inability to cope, illiterate users towards technology and etc.

Change is a critical issue that needs a proper management to handle it effectively. Big majority has confirmed the importance of having proper Project management to handle and monitor the change process.

For embedding new and fresh ideas to enhance the current traditional organization processes, it is suggested to engage new leaders and fresh members to come up with innovative ideas. According to the graph, responses towards the agreement with this recommendation are close to half, where some gave medium importance rate. This shows that new and fresh leaders and members are most likely favorable.

Adequate number of competent staff and specific completion time are important elements to be fulfilled to start any change management process. These two elements can help in measuring the progress of any project and change management conducting process.

Does Change Management help Project to be implemented successfully?

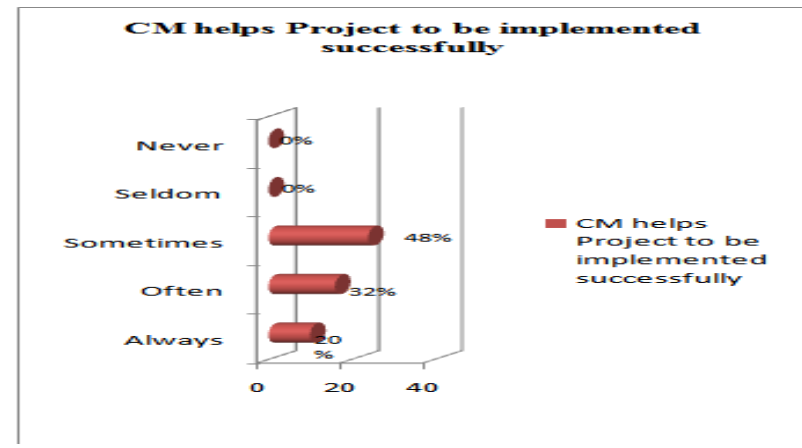

Figure (13): CM contribution in the project success

From Figure (13), the majority have approved that CM could be a good factor that could lead to the project success.

How do you rate your organization in Practicing Change Management?

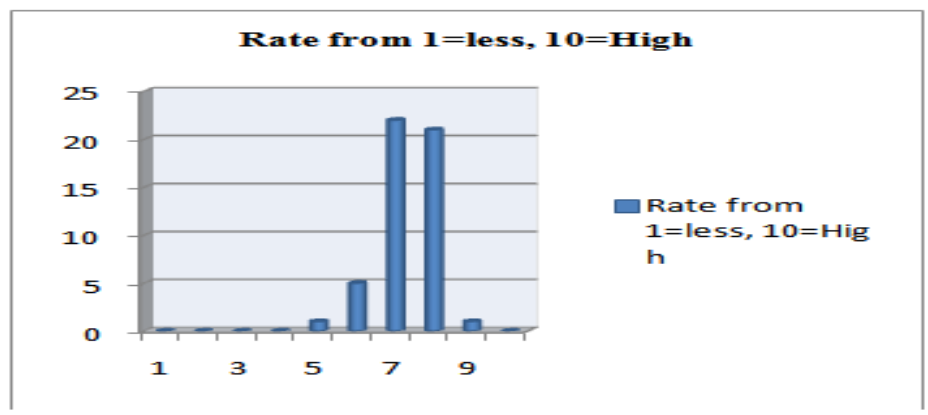

Figure (14): Organization practicing Change management

Extracting form the Figure (14) feedback, it shows that most Malaysian government departments and agencies are practicing and implementing the change management effectively.

\section{CONSTRAINTS \& Limitation}

There are some difficulties faced in this research during distributing the questioner that some people did not understand some terms and concepts which are most important in project change and project implementation. In addition, most of this questionnaires have been distributed online that generates lack of face to face communication with the people and the conversations which makes people aware more about the goal of 
this survey. Another problem faced in this study is lack of cooperation from some people who has experience of this field and that will affect to minimize the number of responses and accuracy. Finally, although there were all these problems or the difficulties of this survey, it achieved more around 50 responses among Malaysian government departments and agencies which is somehow an adequate to measure the significant success factors in project change and in project implementation.

\section{CONCLUSION}

In a nut shell, this survey conducted among Malaysian government departments and agencies to discover the actual success factors that they have been encountered with during the implementation of the project and applying the change management. In another word, there are some successful factors hidden behind successful project and need to be highlighted. Therefore, this study has been conducted to unveil major factors such as people, culture and technology in detail and illustrated how they have tremendous impact on the project during implementation and change process.

As being a government sector which is facing unstoppable growing due to the number of its country people, it becomes very challenging to handle and offer optimal services that satisfy various people needs. Thus, technology power has been very required in various fields in our current time. Big numbers of IT project have been implemented.

Any project regardless of its size and complexity needs to have an effective management over it to ensure that the project intended goals are achieved and its benefits are gained. Additionally, change management is very much appealed to ensure the continuity of any project.

\section{References}

[1] A K Munns and B F Bjeirmi (1996). The role of project management in achieving project. International Journal of Project Management Vol. 14, No. 2, pp. 81-87.

[2] RUNE TODNEM BY (2005). Organizational Change Management: A Critical Review. Journal of Change Management Vol. 5, No. 4, 369-380

[3] Jos H. Pieterse, Marjolein C.J. Caniëls, Thijs Homan, (2012),"Professional discourses and resistance tochange", Journal of Organizational Change Management, Vol. 25 Iss: 6 pp. $798-818$

[4] Caleb Mukhwana (2012). Project Management in Africa. Africa Users Conference.

[5] Research design. Retrieved from http://en.wikipedia.org/wiki/Research design

[6] Ibbs, Y. H. K. a. C. W. (2002). "Project Management Process Maturity „PM...2 Model." JOURNAL OF MANAGEMENT IN ENGINEERING.

[7] (2013) Project management process, URL:http://en.wikipedia.org/wiki/Project_management_process

[8] （2013). "Work breakdown structure.", URL: http://en.wikipedia.org/wiki/Work_breakdown_structure

[9] Scotland, K. Fidelity - The Lost Dimension of the Iron Triangle.URL: http://availagility.co.uk/2009/12/22/fidelity-the-lostdimension-of-the-iron-triangle/

[10] (2013). "Agile software development."URL: http://en.wikipedia.org/wiki/Agile_software_development

[11] (2013). "Extreme programming."URL: http://en.wikipedia.org/wiki/Extreme_programming

[12] (2013). "Software development methodology."URL: http://en.wikipedia.org/wiki/Software_development_methodology

[13] Fatima Munassar, Alyaa. Ghanim., Abdul Rahman Ahmad Dahlan (2013). "Change Management and its contribution to the Success of IT project implementation " IJICTR Vol.3 No.4, April 2013.

[14] Creasey, T. (2013). "Definition of change management helping others understand change management in relation to project management and organizational change." 